\title{
Early Experience with Minimally Invasive Oncologic Surgery at a Peripheral Cancer Centre in North East India
}

\author{
Gaurav Das ${ }^{1}$, Ashutosh Sahewalla ${ }^{2}$, Joydeep Purkayastha ${ }^{3}$, Abhijit Talukdar ${ }^{4}$ \\ ${ }^{1}$ Department of Surgical Oncology, Dr B. Barooah Cancer Institute (Corresponding author) \\ ${ }^{2,3,4}$ Department of Surgical Oncology, Dr B. Barooah Cancer Institute
}

\begin{abstract}
Introduction: The use of minimally invasive surgery (MIS) in oncology in certain cancers has been proven to be non-inferior to open procedures with superior short term outcomes in several randomized controlled trials. Methods: A retrospective study of MIS done for cancers of esophagus, lung, colorectal cancers and gastric cancers was done for the study period $1^{\text {st }}$ Jan 2018 to $31^{\text {st }}$ Dec 2019. Results: A total of 46(54.7\%) procedures were done with the use of MIS out of a total of 84 cases. Trans-thoracic esophagectomy (TTE) was done using VATS in 25 cases (62.5\%). The mean duration of ICU stay was 2days and mean duration of hospital stay was 12days. The mean post-operative pain score was 2. The number of surgeries done by MIS for colorectal cancers was 17(44.7\%) out of a total of 38 cases. This included 3 lap right hemicolectomies, 9 Lap APR, 5 Lap LAR/ULAR. The mean ICU stay was 1day and the mean hospital stay was 11days. The mean pain score was 3. Also performed was one case of VATS left lung upper lobectomy, one case of VATS right lung metastasectomy, 2 cases of lap-assisted distal gastrectomy with D2 lymphadenectomy. Conclusion: The acceptance of MIS in our institute has produced favourable short term results which appear encouraging.
\end{abstract}

Keywords: Minimally invasive surgery

\section{Introduction}

The use of minimally invasive surgery (MIS) in oncology in certain cancers has been proven to be non-inferior to open procedures with superior short term outcomes in several randomized controlled trials ${ }^{1}$. For example, MIS has been associated with less incisional pain and reduced need for opioids, shorter length of stay, as well as lower overall morbidity and improved quality of life $^{2}$.

\section{Materials and Methods}

A retrospective study of MIS done for cancers of esophagus, lung, colorectal cancers and gastric cancers was done for the study period $1^{\text {st }}$ Jan 2018 to $31^{\text {st }}$ Dec 2019. Simple statistical tools were used for analysis.

\section{Results}

A total of $46(54.7 \%)$ procedures were done with the use of MIS out of a total of 84 patients. Trans-thoracic esophagectomy (TTE) was done using VATS in 25 patients $(62.5 \%)$ and the remaining were done using open right lateral thoracotomy 4 patients $(10 \%)$ and trans-hiatal approach (THE) 11 patients $(27.5 \%)$. Conversion to a thoracotomy was needed in 3 cases $(12.5 \%)$. The indications were uncontrolled bleeding in two patients and a left bronchial injury in one patient. Anastomotic leak was noted in 3 patients $(12.5 \%)$. A similar incidence $(12.5 \%)$ of hoarseness of voice due to recurrent laryngeal nerve palsy was noted and it was transient in all instances. The median duration of ICU stay was 2 days (range was 1-4days) and median duration of hospital stay was 12 days (range was 1123days). The median post-operative pain score was 2 (range was 1-4).

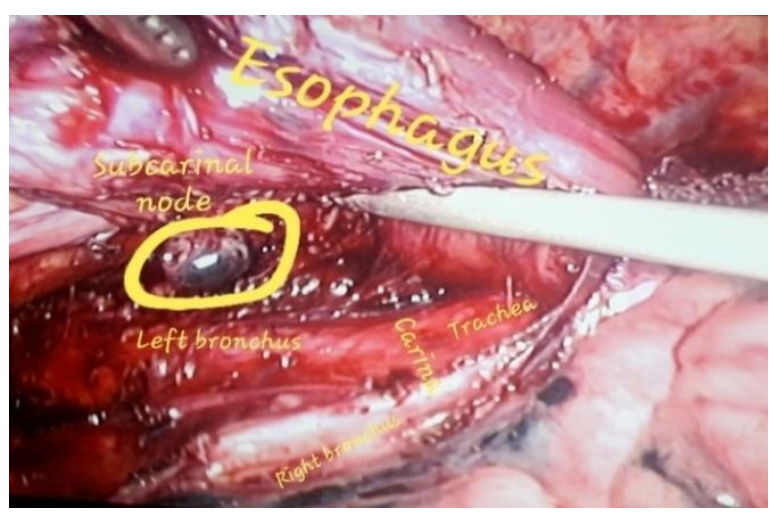

Figure 1: Showing thoracoscopic mobilization of the esophagus (VATS TTE)

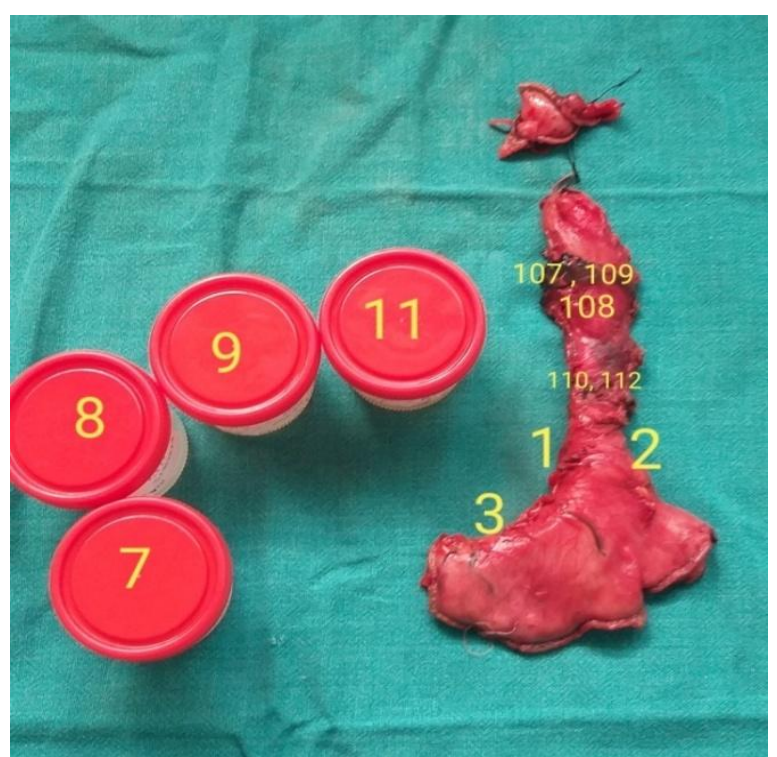

Figure 2: Specimen of esophagectomy 


\section{International Journal of Science and Research (IJSR) \\ ISSN: 2319-7064}

ResearchGate Impact Factor (2018): 0.28 | SJIF (2019): 7.583

The number of surgeries done by MIS for colorectal cancers was $17(44.7 \%)$ out of a total of 38 patients. This included 3 laparoscopic right hemicolectomies, 9 laparoscopic abdomino-perineal resections (APR), 5 laparoscopic low or ultra-low anterior resections (LAR/ULAR). The conversion rate to open procedure was $11.4 \%$. The median ICU stay was 1 day (range was 1-3days) and the median hospital stay was 11days (range was 7-26days). These numbers compared favourably against the open surgery patients, where median values were 2 days (range 1-5days) and 14 days (range 831days) respectively. The incidences of surgical site infections (SSIs) were higher in the open surgery patients (3 vs 1). The median pain score was 3 in MIS patients and 6 in open surgery patients.

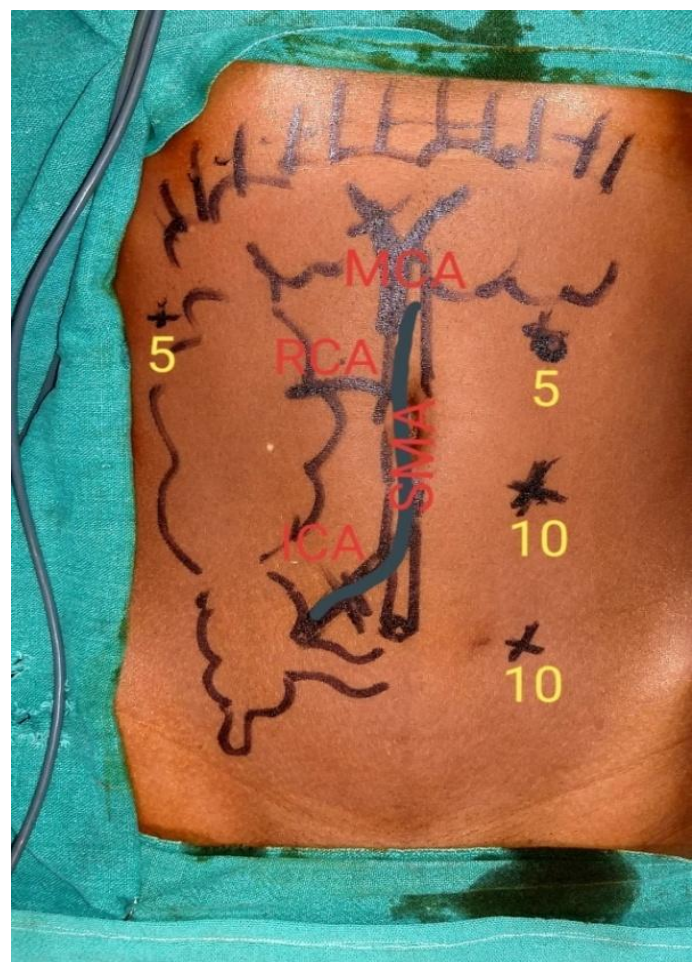

Figure 3: Surface marking of port placement for right hemicolectomy

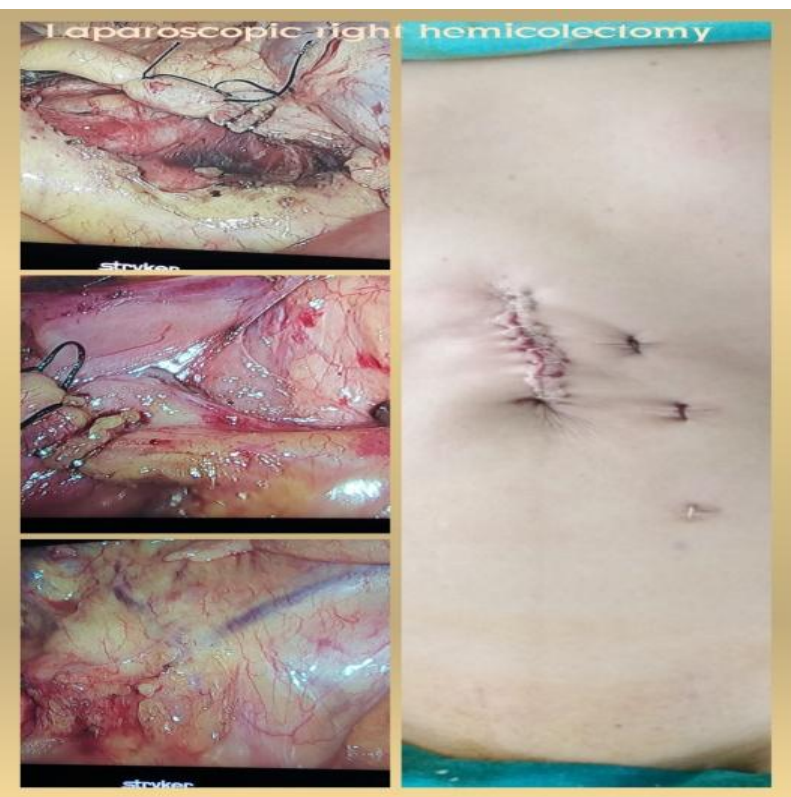

Figure 4: Laparoscopic right hemicolectomy
There was one patient who underwent VATS left lung upper lobectomy, one patient of VATS right lung metastasectomy and 2 patients with laparoscopic-assisted distal gastrectomy with D2 lymphadenectomy.

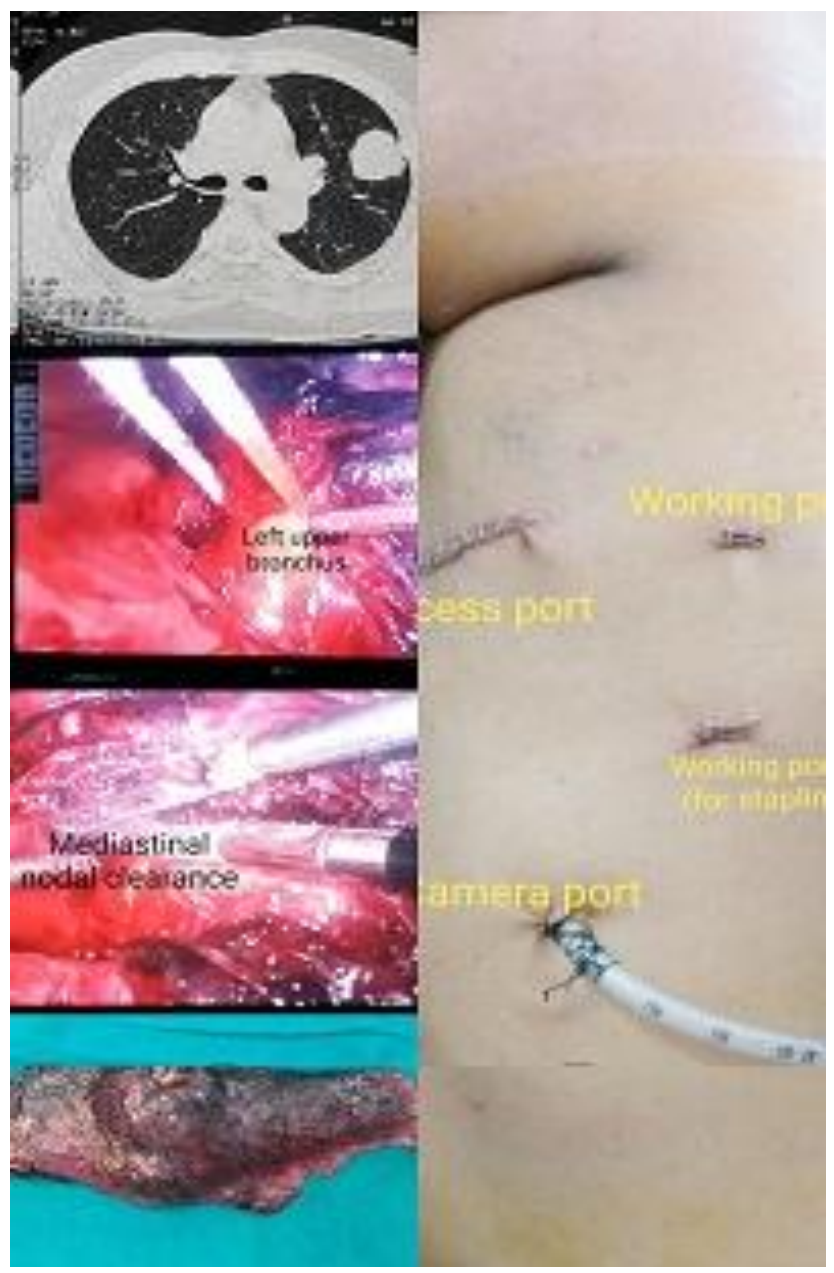

Figure 5: VATS left lung upper lobectomy

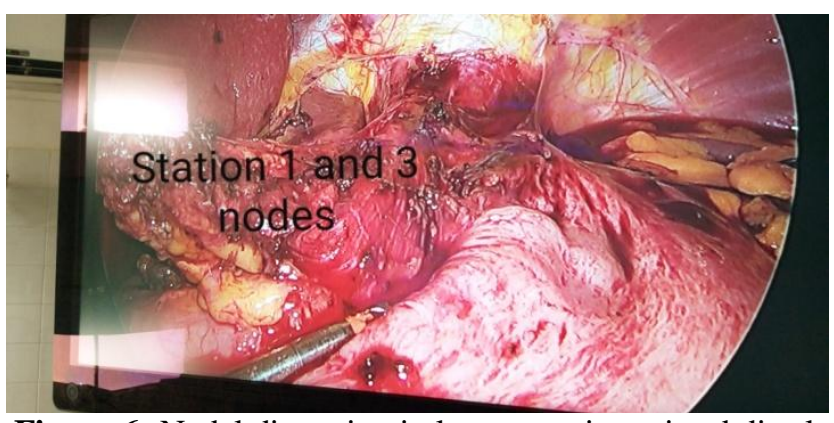

Figure 6: Nodal dissection in laparoscopic-assisted distal gastrectomy

The numbers of MIS surgeries increased in the year 2019 compared to 2018 (Tables1, 2, 3). There was an increase of $56 \%$ in MIS approach in esophageal cancer and $38 \%$ in colorectal cancer resections (Table 4).

Table 1: Showing the number of surgeries for esophageal

\begin{tabular}{|c|c|c|}
\hline \multicolumn{3}{|c}{ cancer } \\
\hline Esophagectomy & 2018 & 2019 \\
\hline Open TTE & 14 & 04 \\
\hline THE & 09 & 11 \\
\hline VATS TTE & 02 & 25 \\
\hline
\end{tabular}

Volume 9 Issue 5, May 2020

www.ijsr.net 


\section{International Journal of Science and Research (IJSR) \\ ISSN: 2319-7064}

ResearchGate Impact Factor (2018): 0.28 | SJIF (2019): 7.583

Table 2: Showing the number of surgeries for colorectal cancer

\begin{tabular}{|l|l|l|}
\hline Colorectal Surgery & 2018 & 2019 \\
\hline Open APR & 09 & 07 \\
\hline Open LAR & 09 & 12 \\
\hline LAP APR & 02 & 09 \\
\hline LAP LAR/ ULAR & 01 & 07 \\
\hline LAP HEMICOLECTOMY & 00 & 03 \\
\hline
\end{tabular}

Table 3: Showing the number of surgeries for other cancers

\begin{tabular}{|l|l|l|}
\hline Other Lap Cases & 2018 & 2019 \\
\hline LAP Distal Radical Gastrectomy & 00 & 02 \\
\hline VATS Metastasectomy & 00 & 01 \\
\hline VATS Left Lung Upper Lobectomy & 00 & 01 \\
\hline
\end{tabular}

Table 4: Showing the percentages of surgeries done by MIS approach, year-wise

\begin{tabular}{|l|l|l|}
\hline & 2018 & 2019 \\
\hline Thoracoscopic Surgery & $08 \%$ & $64 \%$ \\
\hline Laparoscopic Colorectal Surgery & $14 \%$ & $52 \%$ \\
\hline
\end{tabular}

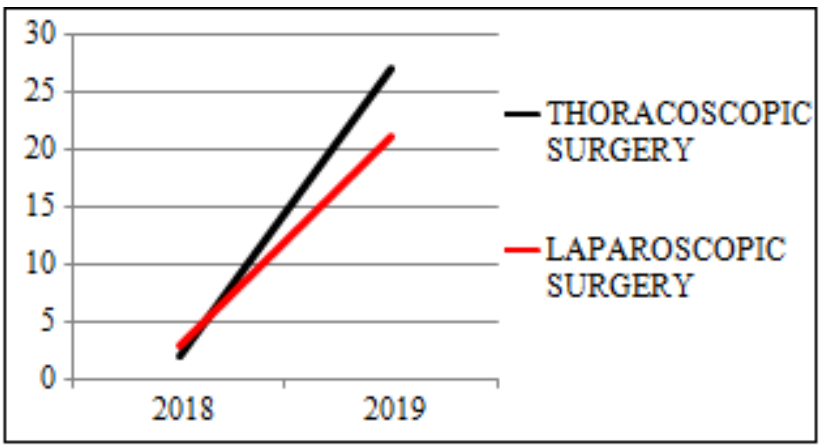

Figure: Showing the increasing trend of use of MIS in surgery at our institute, year-wise.

\section{Discussion}

Minimally invasive surgery (MIS) refers to surgical procedures that limit the size of surgical incisions needed so that the blood loss, wound healing time, associated pain and scarring, hospitalization time, risk of infection, and postsurgical complications are usually less.

Surgery has long been thought of as a "stressor" with associated immunomodulation and possibly derivative effects on cancer progression. Many hypotheses exist regarding the immunologic response to surgery and whether a less "stressful" MIS might result in better oncologic outcomes $^{3}$.

Neoplasms such as early gastric cancer, colo-rectal cancer, and esophageal cancer are now preferentially approached with minimally invasive surgery with decreased pain, lower wound infection rates, better postoperative pulmonary function, and shorter recovery time compared with traditional laparotomy. Robust studies showed that minimally invasive techniques could provide equivalent outcomes compared with traditional open approaches in many cases ${ }^{4,5,6,7,8}$. At our institute, we have incorporated MIS techniques into our surgical practice, as per oncologic indications, in a very steadfast manner, for the last two years, as reflected in the data presented herein. Our experience is still very early and evolving, as we learn more and we hope to report a much bigger dataset in years to come.

We do not have a robot in our institute and our MIS experience is limited to laparoscopic approaches only.

\section{Conclusion}

The use of MIS in our institute has produced favourable short term results which is very encouraging.

\section{References}

[1] J. Fleshman, D. J. Sargent, E. Green et al., "Laparoscopic colectomy for cancer is not inferior to open surgery based on 5-year data from the COST Study Group trial," Annals of Surgery, vol. 246, no. 4, pp. 655-662, 2007.

[2] E. Kuhry, W. Schwenk, R. Gaupset, U. Romild, and J. Bonjer, "Long-term outcome of laparoscopic surgery for colorectal cancer: a cochrane systematic review of randomised controlled trials," Cancer Treatment Reviews, vol. 34, no. 6, pp. 498-504, 2008.

[3] Whitson, B. A., D'Cunha, J., \& Maddaus, M. A. (2007). Minimally invasive cancer surgery improves patient survival rates through less perioperative immunosuppression. Medical Hypotheses, 68(6), 13281332.

[4] M. H. van der Pas, E. Haglind, M. A. Cuesta et al., "Laparoscopic versus open surgery for rectal cancer (COLOR II): short-term outcomes of a randomised, phase 3 trial," The Lancet Oncology, vol. 14, no. 3, pp. 210-218, 2013.

[5] D. G. Jayne, P. J. Guillou, H. Thorpe et al., "Randomized trial of laparoscopic-assisted resection of colorectal carcinoma: 3-Year results of the UK MRC CLASICC trial group," Journal of Clinical Oncology, vol. 25, no. 21, pp. 3061-3068, 2007.

[6] C. G. S. Huscher, A. Mingoli, G. Sgarzini et al., "Laparoscopic versus open subtotal gastrectomy for distal gastric cancer: Five-year results of a randomized prospective trial," Annals of Surgery, vol. 241, no. 2, pp. 232-237, 2005.

[7] Lee HJ, Hyung WJ, Yang HK, Han SU, Park YK, An JY, Kim W, Kim HI, Kim HH, Ryu SW, et al. Morbidity of laparoscopic distal gastrectomy with D2 lymphadenectomy compared with open distal gastrectomy for locally advanced gastric cancer: short term outcomes from multicenter randomized controlled trial (KLASS-02). J Clin Oncol. 2016;34: Supplement 4062.

[8] A. Pennathur and J. D. Luketich, "Minimally invasive esophagectomy: short-term outcomes appear comparable to open esophagectomy," Annals of Surgery, vol. 255, no. 2, pp. 206-207, 2012. 